\title{
Conceiving of addicted pleasures: a 'modern' paradox
}

Authors accepted manuscript, published in the International Journal of Drug Policy. Available at: http://www.ijdp.org/article/S0955-3959(17)30209-8/pdf

\section{Fay Dennis}

\begin{abstract}
Drawing on research with people who inject drugs in London, UK, this article will explore how participants conceived of pleasure, and try to understand some of the tensions that ensued. There is a strong sense in participants' accounts that drug use is at points pleasurable but it should not, or rather, could not be conceived of in this way. As such, the article will reflect on several situations in which pleasure came up during fieldwork but was quickly redirected towards addiction using terms such as 'denial'. Trying to make sense of this seemingly paradoxical dynamic, in which pleasure can be addictive, but addiction cannot be pleasurable, I turn to some of the practices that actively keep pleasure and addiction apart, indeed, in some areas of the addiction sciences, antithetical. That is, a singular account of pleasure is produced as freely chosen (of the 'free' subject) in opposition to the determined nature of addiction (of the automated brain or object). These realities materialise in participants' accounts, but due to their constructed nature they also collapse and multiply. This 'hybridisation' is what Bruno Latour refers to as the paradox of the Moderns. Considering pleasure, however, as both natural and cultural, it is better conceived of as always in tension, expressed by participants as 'mixed feelings', 'love/hate', 'sweet and sour', 'good things and bad things'. Against a backdrop of neglect, especially within the context of injecting drug use, such conceptualisation can help acknowledge pleasure where it is least conceivable and yet perhaps has the most to offer.
\end{abstract}

KEYWORDS: addiction, Bruno Latour, injecting drug use, pleasure 


\section{Conceiving of addicted pleasures: a 'modern' paradox}

\section{INTRODUCTION}

Once labelled 'the great unmentionable' (Moore \& Valverde, 2000, c.f. Hunt \& Evans, 2008), pleasure for many in the 'West', including for drug researchers, health practitioners, policymakers, as well as the media, has been hard to conceive of in relation to illicit drug use (Treloar \& Holt, 2008; Ritter 2014), especially using 'addictive' drugs such as heroin and crack cocaine (Pienaar et al., 2015), and further still injecting these substances (Dwyer, 2008; valentine \& Fraser, 2008). This article, however, seeks to explore where pleasure gets discussed (or not) by participants in a study looking at experiences and practices of injecting drug use and how participants make sense of pleasure in a way that might lead to its wider inclusion in the drug and addictions field. A distinctly 'modern' (Latour, 1993) refrain to pleasure is identified, based on the separation of nature and culture: where pleasure is associated with the 'free' world of subjects, addiction is associated with the realm of objects and the 'determined brain'. The two become antithetical, which makes pleasure, within a context of 'addictive' drug use, hard to exist. In this sense, what is usually considered as ontological becomes political, and several sociomaterial practices take place to maintain pleasure's absence. The possibility of pleasure lies in negating these poles: pleasure/addiction, object/subject, nature/culture. This article therefore explores the ways that 'addiction' and 'pleasure' co-exist in participants' accounts, always in tension. By re-framing pleasure away from 'freedom', the article suggests that wider discussions and possibilities for how drugs get experienced (which can include pleasure among other affects) can take place in drug treatment practice and policy.

\section{BACKGROUND}

According to O'Malley and Valverde (2004), the absence of pleasure in drug research has a long political history based on controlling drug users. They argue this is due to the perceived threat that drug users pose to neoliberal ideals of autonomy and choice. In this sense, pleasure for some drug researchers and practitioners has served as a useful tool in re-rationalising drug use, but this allows for only a very specific kind of pleasure (based on autonomy and choice), which could be neglecting quieter, more subjugated forms. 
O’Malley and Valverde suggest that since the eighteenth century

discourses of 'pleasure' have been linked to discourses of reason and freedom, so that problematic drug consumption appears both without reason (for example 'bestial') and unfree (for example 'compulsive'), and thus not as 'pleasant'. (2004: 25)

O'Malley and Valverde (2004), like much of the work on the neglect of pleasure in the sociology of drug use, draw on Michel Foucault's concept of 'governmentality'. Foucault uses 'governmentality' to explain a decentralisation of power occurring in the 'West' during the eighteenth century in which localised 'technologies of power' started to produce selfgovernable citizens (Foucault, 2007). The concept has since been developed by Nikolas Rose in relation to the neoliberal consumer society, which is seen to be based on 'government through freedom' (Rose, 1999: xxiii). Expanding on this further, in a joint paper by Rose, O'Malley and Valverde (2006), this is the idea that we are not controlled through an impingement of our freedoms, but rather, paradoxically, through an obligation of freedom 'subjects [are] required to be free and [are] required to conduct themselves responsibly, to account for their own lives and their vicissitudes in terms of their freedom' (ibid: 90-91). Within this framework, drug use is seen to be without 'freedom', without 'rationality', and consequently without 'pleasure' (O’Malley and Valverde, 2004).

Pleasure, especially as in the figure of the felicity calculus, is at the heart of liberal constructions of the rational and free subject. Pleasure and rationality are foundationally linked, precisely because the pleasure/pain couple is a given in the liberal constitution of rational calculation.

For Rose (2000), drug users 'are problematic because they throw into question the very presuppositions of moral consciousness, self-control and self-advancement through legitimate consumption upon which governmental regimes of freedom depend' (2000: 321). Therefore, drug users need to be controlled, and hence Reith (2004) observes a paradox in contemporary society where "values of freedom, autonomy and choice have been accompanied by a vitiation of freedom, an undermining of agency and a lack of choice characterised by a number of addictive states' (2004: 283). That is, those that are deemed unable to manage their own choices and perhaps more importantly 'risks' are subjected to various disciplining technologies. For O’Malley and Valverde, this has meant that drugs' pleasures have been replaced by 'craving':

More recently the compulsion of 'addiction', thought to be located in certain brain processes, has been joined by what ostensibly appears to be a proxy for pleasure - as 'craving' has taken the place of other 'impelling' forces. (2004: 34) 
For many working in the sociology of drug use, this has made re-rationalising drugs' pleasures a popular way of de-pathologising drug users. For example, Pennay (2012) challenges 'media and public health discourses which construct drug users as uncontrolled, irrational, irresponsible, and disorderly' (2012: 419), in demonstrating, instead, how participants 'regulated and ordered their bodies during sessions of alcohol and party-drug use' (2012: 417). In highlighting the intentionality behind intoxication, a number of terms have evolved to rationalise the pleasures found in alcohol and other drug use, such as, 'determined drunkenness', (Measham, 2006; Hutton, 2012), 'calculated hedonism' (Brain, 2000; Featherstone, 1991, Szmigin et al., 2008), and more recently 'functional fun’ (Askew, 2016). But is more rationality what we need? And how might this be excluding those forms of pleasure that are not so easily rationalised, and those people experiencing pleasure in drug use that could be described as more dependent?

Schnuer (2013) has criticised research on drug use for focusing on 'rational choice' theories, and more specifically for focusing on pleasure as a purposive and consciously chosen motive for action. Schnuer (2013) argues that this neglects a form of pleasure 'without aims and intentions', what he calls 'overwhelming pleasure'. He draws on a 'moderate reading' of George Bataille who 'attaches great meaning to the absence of the pursuit of something meaningful' (2013: 263). For instance, Bataille's concept of Sovereignty is defined in opposition to the "modern term, where "letting go of control" [was replaced with] "being in control" as the basis of autonomy', and instead defines it as the 'capacity to lose oneself, to disconnect oneself from the constraints of choice' (2013: 263). Schnuer argues that this introduces us to an idea of 'pleasure' as neither rational nor irrational but 'arational', that is, 'disinterested in rationality'. This has a powerful potential for being able to transcend the dichotomy of the 'rational mind' and 'irrational body' in researching the bodily and excessive side of pleasure - permitting 'an immoderate, undisciplined, and arational pleasure to be positive' (2013: 264).

Extending an idea of pleasure beyond the rational, Weinberg considers the agency of the body through its context

wherein the pleasurability of drug effects is not a neurological fait accompli but derives to a considerable extent from perceptions of a felicitous fit between drug effects and the practical demands of specific situations. (2013: 178) 
This fits into Weinberg's (2002) larger intellectual project calling for the recognition of embodied addiction in which 'learning occurs not only through symbolically mediated interpretive work, but through embodied forms of collaborative practice as well' (2002: 14). In his most recent paper, Latour's (2004) notion of the body as 'learning to be affected' is applied to illuminate

the lived realities of embodiment by revealing the body as not only the mechanical medium through which our minds learn but an intrinsically developing and learning faculty in its own right. (Weinberg, 2013: 177)

Weinberg's approach also shares similarities with Duff's recent move from 'context' (2008) to 'assemblage' $(2012 ; 2013 ; 2014)$, in which pleasure is seen as one of many e/affects enacted in the specific coming together of 'diverse objects, spaces, actors [human and nonhuman] and affects' (Duff, 2012: 145). Duff's work is important here for developing a relational approach to pleasure which ontologically disrupts any notion of rationality.

Singling out one actor in this network - such as the consuming subject - without acknowledging the agency of the myriad additional actors involved in this consumption merely reinforces the quaint dogma of rational choice. (Duff, 2012: 155)

The relationality of drug effects, such as pleasure, is reflected in his research participants' narratives on ecstasy:

Implicit in these narratives is an affective and relational account of the phenomenology of ecstasy use, one that downplays the material properties of the substance itself in highlighting the relational construction of drug-related pleasures. (Duff, 2012: 153, original emphasis)

In this sense, alcohol and other drugs are "not the same thing from one network to another, or from one event of consumption to another' (Duff, 2013: 169). Therefore, drugs do not cause pleasure, and people do not choose pleasure, but it is made in these contexts.

Interestingly, these 'overwhelming', embodied and relational forms of pleasure are often less communicable, that is, for Schnuer, 'pleasure that is without need, without motive and without clear function, is hard to articulate and, therefore, barely accessible to discourses dealing with addiction or problematic use' (2013: 266, original emphasis). This incommunicable side of pleasure that exceeds or precedes words is supported in various empirical studies (e.g. MacLean, 2008; Nettleton et al., 2011). In his study of club spaces, Duff (2008) says 'what is perhaps most striking about research respondents' accounts of the various 
sensory pleasures associated with the use of illicit drugs is the difficulty most had articulating the precise nature and experience of these pleasures' (2008: 389). Demant summarises this issue more generally in stating that 'when studying bodily experience like taking drugs... it is hard for the actors to verbalise what is going on' (2009: 31).

It is against this backdrop that the study at hand employed new kinds of methods to attune to these quieter and often more subjugated forms of pleasure that are less consciously and cognitively accessible and thus communicable and conceivable.

\section{AIMS AND METHODS}

This article draws on a qualitative research project in London, UK that sought to explore experiences of injecting drug use, with a particular interest in pleasure as a neglected area of research in the sociology of drug use and harm reduction. The project used a 'montage' of methods, including 'creative' interviews with people who inject drugs, participant observation over a six month period at a community drug service, and in-depth interviews with staff members in various areas and positions of drug service provision across three London boroughs ${ }^{1}$. Although this paper focuses on the former interview accounts, it is important to note that the wider methodology informed the direction and sensibility of the research and analysis. Through these methods, a subtle practice of 'noticing' is used to account for the quieter modes of pleasure as outlined above.

For the creative interviews, thirty participants were recruited through posters and word of mouth at two community drug services in different parts of the city (chosen for their higher concentrations of injecting drug use $)^{2}$. This included twenty men and ten women, aged between 28-60 years old, from a range of social and ethnic backgrounds. Fifteen participants currently

\footnotetext{
${ }^{1}$ Ethical approval was granted by the London School of Hygiene \& Tropical Medicine Ethics Committee (ref. 7039) and the National Health Service Regional Ethics Committee (ref. 14/LO/0184).

${ }^{2}$ Notably, because I also recruited via word of mouth, not all participants were 'in treatment' at these services. Treatment for heroin in the UK context usually refers to receiving an opiate substitute prescription and psychosocial support in the form of key work, delivered by a 'substance misuse practitioner', or newly relabelled 'recovery worker', at a community, mostly third-sector run, drug and alcohol service. There are residential detox and rehabilitation facilities but these have a more lengthy and competitive referral process due to the higher cost implications. The sites I used for recruitment were community drug services that offered substitute prescribing, key working, counselling and harm reduction services such as a needle exchange and onsite nurse appointments for wound care.
} 
(defined as within 4 weeks) injected heroin (six also smoked crack cocaine), thirteen injected heroin with crack cocaine ('speedball') and two injected pharmaceutical heroin or diamorphine. The interviews lasted approximately 1.5 hours and participants were reimbursed $£ 15$ for their time and travel costs.

These interviews centred on the embodied experiences and practices of injecting drug use and harm reduction. Keen to explore the less communicable aspects of pleasure and other affects, I asked participants to draw their bodies on an A1 piece of paper and map out what they would be feeling and doing, and what would be going on around them before, during and after using drugs (see also Dennis, 2016a, 2016b, 2017). A practice of 'noticing' was employed to pick up on those aspects that get communicated beyond word or sound (listening and language) and drawing (seeing) in enlarging a sense of what is it to be a research subject, that is to say, I tried to use a fuller notion of my senses, attuned to affect, in realising new modes on subjectivity and experience. In Ordinary Affects, Stewart (2007) introduces 'noticing' as a method for getting closer to the sensations, intensities and textures through which ordinary life is experienced (Coleman and Ringrose, 2013: 4). I use it here to refer to a methodological alertness to bodies - an entanglement of bodies, human (e.g. mine, participants') and nonhuman (e.g. research materials) - in producing the bodies and experiences that are eventually made knowable in this research.

The interviews are described as ‘creative' following Mason's (2010) coining of the term to describe interviews that produce additional data to the spoken word. But they also have another meaning, more in line with Lury and Wakeford's (2012) methodology of 'invention', in which research is also creative through the realities it enacts. It is in this sense that I employ 'montage' over more usual descriptions of combining methods via triangulation (to reach a more valid account). Originating from film studies, montage is an editing technique, or " joining together of different elements in a variety of combinations' (Suhr and Willerslev, 2013: 1), which disrupts a linear logic of time and space. It is extended here to account for the 'crafting' process in social research and the contingency of what gets made (Law, 2004; Coleman \& Ringrose, 2013).

Where the creative interviews 'noticed' embodied experiences of injecting drug use, participant observation 'noticed' and made other realities possible; for example, the ways addiction and pleasure got enabled or constrained in the drug service, in particular, through the material environment. The interviews with service providers sharpened this focus as workers 
talked me through the difficulties of entertaining drugged pleasures in the service. It became clear that this was not a place for pleasure, and I have no doubt that, like one worker said, most people at the drug service 'presenting for treatment' had 'forgotten how it was to enjoy their use'. Extending a creative and more expansive and entangled idea of method based on noticing, I not only bring in reflections, and stories, but other 'ways of knowing' or technologies of knowing in the form of the addiction sciences. Such technologies, or even bodies, contribute again to those bodies and experiences made knowable in the research, and thus although seemingly outside of these discussions of conceivable pleasure, they affect participants and are even drawn upon by participants in interesting and revealing ways.

\section{APPROACH: 'WE HAVE NEVER BEEN MODERN'}

In thinking through participants' accounts, trying to make sense of the tensions between pleasure and addiction, I kept coming back to Bruno Latour's seminal text: We Have Never Been Modern. As its relevance gets fleshed out below using participant accounts, I will only briefly set up the position here. Situated in the anthropology of science, Latour concerns himself with the worlds of nature and culture. But rather than giving science a cultural interpretation, he argues that we have never made such separation. Drawing from Shapin and Schaffer's 'Leviathan and the Air Pump', Latour examines the Modern Constitution bequeathed to us by thinkers such as Thomas Hobbes and Robert Boyle.

They are like a pair of Founding Fathers, acting in concert to promote one and the same innovation in political theory: the representation of nonhumans belong to science, but science is not allowed to appeal to politics; the representation of citizens belongs to politics, but politics is not allowed to have any relation to the nonhumans produced and mobilized by science and technology. (1993: 28)

Latour argues, however, that Shapin and Schaffer fail to do justice to the 'genius' of their comparison - Hobbes and Boyle, the Leviathan and Air Pump, politics and science suggesting that they 'submit to politics' (1993: 25). The essential point of this Modern Constitution, he argues, 'is that it renders the work of mediation that assembles hybrids invisible, unthinkable, unrepresentable' (1993: 34). The work of purification - nature - must remain separate from the work of mediation - society (1993: 32). Taking up this 'lost opportunity', Latour sets about redrawing or rather removing this line between politics and science, the human and nonhuman, culture and nature. The new constitution is to be built on 
hybrids - quasi-objects (like the missed opportunity of the air-pump) and quasi-subjects. He seeks to explore how hybrids get purified, or made as 'single'. For me, this speaks to the relationship between drugged pleasures as freely chosen, of the subject, or as automation, of the brain. Currently, 'the immanence of society' - 'we are totally free' - protects the 'transcendence of nature' - 'we can do nothing against Nature's laws'. In other words, our notions of freedom and subjectivity protect our ideas of automation and objectivity, and thus 'pleasure-as-free' helps to bring about 'pleasure-as-automation'. But as I will go on to explicate, we have never been modern, and pleasure has never been free.

\section{ANALYSES}

The more we forbid ourselves to conceive of hybrids, the more possible their interbreeding becomes - such is the paradox of the moderns.

Latour, 1993: 12

FD: So do you see it as something which is pleasurable?

Tom: Yeah, sort of, yeah, I mean, when I was stressed out over the weekend, when I had my 28-day 'notice to quit' [eviction notice] and all that, the same way that someone would come in and reach for the brandy or the whisky and stuff. I'm not a drinker and I find the effects of hangovers, I can't really cope with, but in the same way as someone would reach for the whiskey bottle, I reach for the telephone and get myself a couple of bags [of heroin].

FD: Yeah, but, do you do that also when you're like in a good mood, and you're just like ahh that sounds like a good idea or is it always when you're feeling stressed?

Tom: Well, it's my addiction, so, it's my kind of 'drug of choice' so yeah it goes both ways, good mood and bad mood, when I'm in a good mood, I could be in a better mood if I had a couple of bags.

Tom was a long-term heroin injector and recipient of the opiate substitute, methadone. Despite being on this medication, he continued to inject heroin. As Tom's response highlights, in asking about pleasure, I was invariably met with something more complicated, and as I tried to pin this elusive affect down, it escaped definition. I grappled with pleasure, at different points of the project, as a matter of the body (somatically produced and felt), a matter of politics (its existence being dependent on the political context), and language (neoliberal discourses of 
reason and rationality restrict corporeal pleasures, see Pennay, 2012). In other words, I have tried to understand it in social, material and discursive ways. Above, I try to attach it to something 'social' - a pleasure that can challenge the dominant discourses of addiction, one that is done in 'good moods', out of choice, as opposed to a negative conception of drug use, done out of compulsion. But, what I have come to realise, in listening closely to participants' explanations, is that pleasure is at once all of these things, and how it emerges in these conceptualisation exercises elides such divisions. For Tom, pleasure cannot be disentangled from addiction, for it is 'real' ('my addiction'), but also contingent on politics (he accounts for his drug use in terms of normalising it - 'the same way as somebody would reach for the whiskey bottle' - which perhaps indicates an awareness of the contentious political context of drug use) and language (he explicitly uses the term 'drug of choice', which is a common trope in drug services, and indicates how he has come to understand and experience his drug use through such discourses). In this sense, pleasure is at once 'real, social and narrated' (Latour, 1993) or as Deleuze and Guattari put it, there are 'semiotic flows, material flows, and social flows simultaneously' (2004: 22). In trying to deny this hybridity, that is, in what can be seen as a distinctly 'modern' disposition towards a single explanatory frame, the complexity just seemed to proliferate.

Through this, I try to make sense of another seemingly paradoxical dynamic at play in the research: pleasure is addictive but addiction cannot be pleasurable. There was a strong feeling in the fieldwork and in people's accounts that drug use was at points pleasurable but it should not, or rather, as will become clear, could not be conceived of in this way. Participants often spoke of the pleasures of their drug use, but then quickly followed this with a 'but' to indicate the many negative components. Participants would talk about their drug use, and pleasure would slip in, or participants would talk about pleasure, and addiction would force its way in. These verbs are carefully chosen as participants' affective responses, when changing from narratives of pleasure to addiction, were often more sudden and intrusive. For example, in Lucy's account (to come) she begins to get upset when negative memories suddenly surface (cutting her sentence off mid-flow). However, rather than viewing these positive and negative experiences as separate, pertaining either to pleasure or addiction, they appeared to be in constant tension.

The analysis to follow tries to make sense of these tensions. First, I will reflect on a provocative situation that happened during the planning stages of the research, which highlights the extent to which pleasure was an uncomfortable interjection in the context of addictive drug 
use. Second, I seek to understand this encounter through an exploration of how pleasure and addiction are being kept apart, indeed, in the addiction sciences, how they are being made as antithetical. I consider how a singular account of pleasure as freely chosen (of the 'free' subject) is produced in opposition to the determined nature of addiction. I will then look at how such realities are known in participants' accounts, but due to their constructed nature, how they also collapse and multiply. A concept of freedom is key to this construct as I see it, but in a very different way to 'governmentality': instead of the paradoxical 'governance through freedom', there is a 'modern' (Latour, 1993) paradox, where pleasure relies on a singular account of subjective freedom that does not exist.

\section{'Pleasure/addiction'}

The antithetical relationship between addiction and pleasure started to reveal itself in a conversation with a manager and a group of service users during the planning stages of my research. Let me briefly tell this story as a way of framing what is to come.

I was invited to present my proposal at the monthly regional service user committee to gain the group's feedback and, as part of the governance of research, to gain their approval for the study to go ahead. The twelve members, who were seated around a large boardroom table, had read the research proposal in advance. The manager raised concerns, saying that the project's interest in drugs' pleasures sounded more relevant to a group of young people sitting around getting 'stoned' on cannabis than heroin or crack cocaine users in the midst of addiction, and this was discussed amongst the group. The Chair, who described himself as a recovering heroin addict, talked about how he did not know anyone who would see their drug use as pleasurable, and if they did, it was just a 'superficial' aspect, and used as a mechanism for denying the more underlying issues. The concept of denial, which is often used in Narcotics Anonymous rhetoric and psychodynamic-influenced therapies was frequently invoked (see Carr, 2011, for an excellent ethnographic account of the work denial does in producing treatment subjects). In this sense, pleasure was not a legitimate concern, or, as a concern, it was only worth exploring in terms of what it was deemed to be 'covering up'. This sparked a long discussion about the harms that drug use had caused to the members and other people they knew. 
It seemed that pleasure was just not that relevant, that is, until one man, sitting across from me, and waiting for a moment's silence, suddenly interrupted, and said that as soon as injecting was mentioned, a 'pleasurable sensation', what he described as a 'tingly', took place at his old injection site. Suddenly, much to people's surprise, pleasure had entered the room. I think he was trying to express the latent desire that he still feels towards his old drug use, a visceral response that reappears at unsuspecting moments (see also Harris, 2015). Although he went on to recount some of the difficulties (living in a crack house) and tiresomeness of being in 'full blown addiction', he also spoke about the excitement of those days. His response suggests an embodied support for the relevance of pleasure even in dependent drug use. It was brave of him to speak about his pleasurable embodied memories, which are often shut out (Harris, 2015), especially as it was also clear that other people were not going to be so receptive. And, indeed, his response was moved on from quickly. Pleasure undoubtedly occupied a difficult space and needed to be managed carefully.

For me, this managed absence links up to the way 'modern' addiction sciences divide drug use between 'liking' versus 'wanting', in which pleasure, or rather, a lack of it, becomes a defining feature of addiction. Addiction, according to this theory, is a reward-system dysfunction. Although 'wanting' and 'liking' can be linked, they are said to reside in separate parts of the brain and function independently: 'wanting' is seen as 'incentive salience' whilst 'liking' is seen as 'subjective pleasure'. In terms of 'objective' pleasure, 'rewards may influence behaviour even in the absence of being consciously aware of them' (Berridge et al., 2010). In other words, 'wanting' is a matter of automaticity, which is 'objectively' known (for example, through PET scans), beyond conscious awareness, whilst 'liking' is more 'subjectively' and consciously known and governed. Over the course of using drugs, the relationship between 'liking' and 'wanting' is seen to change, with 'wanting' increasing and 'liking' decreasing as the drug use moves from 'casual' to 'compulsive' (Berridge et al., 2010: 16).

The lack of freely chosen pleasure becomes a defining feature of addiction. This is evident in the flourishing area of research on 'craving' as a phenomenon of the 'dysfunctional' reward system, which is again isolated from pleasure: instead of 'subjective' pleasure, there is an 'overstimulated' reward system leading to 'impaired cognitive function' and 'uncontrollable cravings' (Nature, 2014). Therefore, to return to our unexpected encounter with pleasure in the service user group, an embodied pleasure entered where it did not belong. As such, it was carefully managed, and even I did not know how to respond. Besides acknowledging his 
feeling, I was at a loss with what to say. There was an uneasiness about the atmosphere, which perhaps reaffirms at an affective level the strength of this antithetical dynamic between pleasure and addiction. But this is by no means a 'natural' distinction, as the situation also highlighted the proactive work being done to keep normal or 'free' pleasure (e.g. the social cannabis use) away from an 'addictive' pleasure - that is, we are told, 'pleasure' cannot really exist ('denial') for those using drugs in a 'dependent' way. However, ironically, these very practices of maintaining the divide are what also expose its fallacy. I will now try to make sense of how pleasure gets made as antithetical to addiction and the complexities that proliferate as a result.

From a critical sociological perspective, this could be seen in terms of what O'Malley and Valverde (2004) have identified as a link between discourses of pleasure and freedom in the governance of drug users. A notion of freedom is central to their argument and governmentality more generally, which in 'advanced liberal' societies is said to operate paradoxically through freedom. As mentioned above, Nikolas Rose has written extensively on the matter and explores various ways that freedom is used in contemporary society to produce particular types of governable citizens. This work is summed up in a collaborative effort by Rose, O’Malley and Valverde:

Rose (1992) argued that central to contemporary strategies for governing the soul was the creation of freedom. Subjects were obliged to be free and were required to conduct themselves responsibly, to account for their own lives and their vicissitudes in terms of their freedom. Freedom was not opposed to government. On the contrary, freedom, as choice, autonomy, selfresponsibility, and the obligation to maximize one's life as a kind of enterprise, was one of the principal strategies of what Rose termed advanced liberal government. (2006: 90-1)

Neoliberal pleasure is intrinsically tied up with notions of freedom, rationality and reason. It is within this framework that drug use is seen to be without 'freedom', without 'rationality', and consequently without 'pleasure' (O'Malley \& Valverde, 2004). This chimes with Eve Sedgwick's observation that 'the object of addiction has become precisely enjoyment of "the ability to choose freely, and freely choose health"' (1993: 132). By this, she means, 'addiction' has proliferated as the polar opposite of 'free choice' - 'so long as "free will" has been hypostatised... for just so long has a hypostatised "compulsion" had to be available as a counterstructure always internal to it' (1993: 134). Consequently, pleasure (as free) and addiction (as compulsion) emerge as antithetical. And in many ways, a categorisation of 'recreational' and 'dependent' drug use still prominent in drug research serves to perpetuate this separation. 
Therefore, in mentioning pleasure in the interviews, I had inadvertently imported and given voice to a notion of 'pleasure-as-free', which meant pleasure often got denied in light of addiction or accepted in recourse to recreational drug use. For example, Mike, who injects heroin and crack cocaine ('speedball'), says:

Yeah, it's more recreational now than habitual. And for once it feels good to be able to have money and know that you can do it if you want to do it. If you don't want to do it, it's fine. I sit there and think to myself, I don't get many cravings these days, thank god, but when I do, when I do think about it sometimes, or if someone mentions it, and I think well I haven't used for 5 days or over a week, you know, so why do it now, so I'm not easily lead into it, I'll only do it when I want to do [...]. It is more for just like a quick buzz, a quick euphoria, to have a good time, rather than like having to do it.

Mike validates his pleasure through several contrasts, including 'recreational'/'habitual', 'cravings'/'want', 'want to'/'need to', and 'quick buzz' and 'good time'/'having to'. Pleasure exists in light of a certain freedom, so its demise comes about in relation to 'obsession' and being overtaken by the 'brain'. Malik, who also injects 'speedballs', says:

Pleasure does come into it, it did come into it, but I tell you now, for the last three years of so, no, it has not been pleasurable. There's the obsession in me to use anyway, cos I've done it for so long, I will obsess over it. And my brain will make these lovely, I'll remember the good bits.

Even though the participants would meet the DSM-V (American Psychiatric Association, 2013) criteria for an 'addictive disorder', they often drew on the dichotomy between recreational and addictive drug use in distinguishing their practice as pleasure-seeking or within their control, rather than addiction. For example, Ajay says:

It can be habitual, it depends how strong your soul is, like if you choose to be a waster, like obviously you've seen wasters, but, err, you've obviously done other interviews with other people, and obviously their body doesn't look well, they don't eat properly. There's different levels [pause], I use because I want to use, not because I'm a street junkie, I use because I enjoy using.

In an important text by Eduardo Viana Vargas (2010), he cautions researchers against asking why people use drugs due to its susceptibility to pathologised responses. 'It's not enough to ask "why do people use drugs?" and "what is the meaning of drugs?", which is seen to lead to "answers usually premised on "error", "lack" or "weakness"” (2010: 210). It is in this sense that I would also add a warning about how pleasure, in opposition to pathology, that is, 
'pleasure as free', gets evoked in such questioning, and, as a counterpoint, can reproduce pathologising and stigmatising identities. For example, Ajay refers to a 'strength of soul', which is lacking in 'street junkies'. Therefore, following Duff (2014), I have come to conclude that I was asking too much:

the trouble with conventional approaches to drug use is that they ask rather too much of the drug user. The user bears responsibility for most of the dynamics of consumption, and subsequently remains culpable for any of the harm [but also pleasure] generated therein. (2014: 142-3, parenthesis added)

I was asking participants to reflect on something they were not entirely in control of. Indeed, thinking is a process that is not decided by thought alone. It is perhaps not that surprising then that just as easily as 'pleasure-as-free' came into conceptualisation it started to slip away. That is, the more we try to make separations, the more we generate hybrids. Following both Vargas's (2010) use of Gabriel Tarde and Duff's (2014) use of Gilles Deleuze, pleasure is not stable, but a matter of the drug using event, which is anything but freely chosen (Dennis, 2016; 2017). Therefore, in reifying the subject by asking him/her about pleasure, particular conditions were borne out. Of interest here is namely a dichotomy between pleasure and addiction. But in letting this go, or simply 'noticing' what was brought up in other less directed parts of the interview, the dichotomies started to unfold, that is, a 'liking' versus 'wanting' became unstuck, indeed, nonsensical. Some participants conversely talked about their 'addictive' drug use in terms of pleasure, in which, going against the dominant narrative, they continued using because of the pleasures rather than compulsion. For example, talking about her recent move to heroin injecting from smoking, Gwen says, 'actually I'm stoned, this is nice, so it's a bit addictive in that way, you want to do it again'. 'Speedballing' (injecting heroin and crack cocaine together), for most participants, was felt to be particularly enjoyable and addictive: 'as soon as I started doing the speedball, I like it so much, but it makes me do one after the other after the other' (Grigor).

Even more defiantly, 'the addict' was seen as a discerning pleasure-seeker, for example, Mike says: 'Well, the addict inside me is happy, because I'm getting a good bit of thing [crack] for once'. And some of Mike's more dangerous decisions were taken out of pleasure rather than 'need': 
I mean when I first did my groin I didn't need to, I weren't in a situation where I had no veins left, I did, but, again, my friend was doing it and you know, I said what's the difference and he said 'oh yeah, it hits you harder, its stronger, and hits you so much quicker'.

A similar sense of pleasure-seeking, rather than necessity or 'need', can be seen in Meg's account of neck injecting:

Meg: I have used my feet and I have used my neck, I've never used my groin ever.

FD: Was your neck because you couldn't find... [she pre-empted that I was going to say a vein]

Meg: No, it wasn't that, someone said oh you get a better hit, it goes straight to your head, and they did it for me, I didn't do it on my own... It does go to your head quicker, I suppose because it's nearer your brain.

Trying to make sense of this antithetical dynamic of pleasure/addiction, as both brought into being and collapsed by participants, a theory of governmentality does not seem to go far enough. It tries to see addiction as a matter of discourse in a way that does not take the materiality of injecting seriously, which both neglects other parts of the drug assemblage (beyond discourse) and the somatic feelings enacted. For instance, Sedgwick (1993) says:

The locus of addictiveness cannot be the substance itself and can scarcely even be the body itself, but must be some overarching abstraction that governs the narrative relations between them. (1993: 131)

For Bunton and Coveney, these abstract tendencies are seen in relation to the wider dichotomous make-up of the drug field:

Psychology and neurophysiology have developed biological foundations for emotions, including pleasure, as an inherently human phenomenon. Central neurological pathways are credited with the passage of pleasure-receiving signals, and specific parts of the brain have been identified as centres where pleasure is registered (Warburton, 1994). By contrast, sociologists have situated pleasures in time, space and specific discourses seeing pleasure as a socio-cultural construction. (2011: 11)

From what I have seen, heard, and crucially, 'noticed' in this research, there are clear inadequacies in both the 'biological' and 'social' models, as both fail to cope with the complexities of pleasure-addiction. This has encouraged me to think again about this divide, going beyond governmentality, to think about 'pleasure as freely chosen' in another way. Rather than understanding 'freedom' in the neoliberal sense - as a paradox based on 
'governance through freedom' (freedom as an overarching discourse) - I have come to consider 'freedom' through a distinctly 'modern' paradox. Through Latour (outlined above), we have never made the separations between nature and culture that we so unrelentingly follow. Where post-modern theories have tried to eradicate such binaries in recourse to social or discursive construction, Latour argues that they have never existed. Even though the 'Modern Constitution' works tirelessly to make pleasure seem 'freely chosen' (of the subject), in participants' conceptualisation, it is always tied to something more. The paradox is that the more we try to make these separations, the more the boundaries collapse and complexities proliferate.

\section{Pleasure-in-tension: 'It's a really lovely feeling but my god the crap that comes with it'}

The article so far has drawn attention to how addiction and pleasure get made as antithetical, both in addiction sciences and drug services. But emblematic of this construction, we have also seen how the binary gets complicated in participants' accounts. Whether pleasure exists for people to talk about is neither natural (given) nor cultural (performative), but a product of networks, in some more real than others. I will now look further at how these complexities manifest in two accounts from Lucy and Ajay, who encapsulate these tensions in different ways. As they move through different networks of bodies, discourses and things, different affects were produced. In talking about pleasure, Lucy and Ajay tried to separate out this affect from others, but, true to its 'modern' construction, this was not possible, and the complexity or 'crap', to use Lucy's term, multiplied. This brings about a tension in which talking about pleasure becomes difficult, not because it does not exist (in absolute terms) or does not belong (in a governmentality sense), but because it is always in the process of becoming something else (i.e. caught in a network, which, with the slightest change, produces different affects). Pleasure is most literally in tension. I quote Lucy's words in full, as the vibrancy and nuance of the account would be lost if paraphrased.

Lucy: ...But then I slipped back into gear because it was, it's a really weird mistress, or whatever they say, you just think you can leave it and I hope to beat it one day, but it's something that, unfortunately, it does do what it says. It does wrap you up in cotton wool.

FD: Can you tell me a bit more about these feelings? 
Lucy: Well the first time I took it, it is orgasmic, I felt like I was floating on the bed. Like, it was, because he [her partner] started before me, he was quite cross, 'you've got that first feeling', and getting really jealous. And I thought 'oh my god' (rolling her eyes back, suggesting an overwhelming pleasure)... but I don't want to advertise it, I'm just saying... but that's what you're chasing. But then, when it comes to, what's so dangerous about it, it's weird because my sister was very good at the beginning because she had a boyfriend who was very much into heroin and she was so scared for me, she was like please don't go into that extent, and of course you lie to people and say 'oh I'm not', but I was holding down jobs and (stops suddenly). But even though I keep talking about the good side of it, I have such (starts to stutter/quiver), as soon as I think about it, I have such mixed feelings about it, it's a really lovely feeling but my god the crap that comes with it, the stress of getting the money, going to the (cuts off), hiding the secret, taking something, having a hit in the toilet, not having gear, going home dripping, trying to hold down a job where you're hallucinating because you're withdrawing and pouring with sweat, and someone saying can you fax this and you're just thinking I want to go, I want to go, but once you're comfortable at home and you've got all your paraphernalia, it's lovely. [my emphases]

To reiterate, Lucy says, 'as soon as I start thinking about it, I have such mixed feelings, it's a really lovely feeling but my god the crap that comes with it'. She then elaborates on some of this 'crap'. For me, this highlights the difficulties participants found in separating out not only the more immediate feelings from the more lasting, the bodily from the social, but also, more importantly for this article, the enacted from the conceived. This is not because they are separate but precisely because they emanate together. There is something in the conceiving itself which puts pleasure in tension - 'as soon as I start thinking about it' -in which it is attached to addiction discourses, painful withdrawals, social stigma etc. As mentioned above, thinking is the effect of forces that are not decided by thought alone. Instead of starting with any 'singular' forms of addiction (as compulsion) or pleasure (as free), let us attend to the networks in Lucy's, and another participant, Ajay's accounts that produce these thoughts, and thus what this could say more widely about how people come to think about pleasure in drug using practices, and how this could enable alternative (and more positive) ways of thinking, talking and ultimately, doing drugs.

For Lucy, as she describes above, it is in being caught up in networks of physical dependency, changing family dynamics and negative social attitudes that things become 'dangerous'. More specifically, it is in lying to her family, 'hiding the secret [of using]', 'the stress of getting the money', 'having a hit in the toilet', 'withdrawing and pouring with sweat' 
and 'trying to hold down a job'. The sweat, toilet, and fax machine are particularly prominent and powerful actors. The discourses connected to the toilet means that having to use it for anything other than its purpose is highly stigmatised. Sweating is attached to a particularly gendered discourse of shame. And the fax machine affords an office (and arguably gendered) professionalism that Lucy is struggling to conform to. But once she is at home with her paraphernalia, it's 'lovely'. As these networks change, from the toilet-sweat-fax machine to the syringe-home-heroin, Lucy's feelings change and hence, on reflection, they begin to overlap and coalesce. This reflects Annemarie Mol's sentiment that 'as actors come to participate in different "networks", discourses, logics, modes of ordering, practices, things get complex' (2010: 260). Lucy tries to separate (in line with the Modern Constitution) thought from the world, past from the present, and bodily from the social, but this is not possible and causes tension. To revisit Latour, and Deleuze and Guattari, everything is at once material, social and political.

These tensions are further seen in Ajay's account, which are highlighted in the changing position of the drug, heroin, from 'golden brown' to a 'brown bitch'. Like in Lucy's account, Ajay starts off by conceiving of heroin in terms of pleasure, but it quickly becomes about more (or less). Using the body mapping to tell his story, I asked, in referring to his drug use, 'and then how does that make your body feel?', and Ajay replied, 'Right...shall I do another one [body map]? He explains that his first picture (right hand side of Figure I) would be before using drugs: 'so this is before: 'waiting for your dealer'. 'And this new one is about?' 'After, this would be, "after", "under the influence" - how do you spell "influence"?' He then started writing some song lyrics (left hand side of Figure 1), and said: 'It's true - have you heard it golden brown, texture like sun, brings [lays] me down with my masheeba [mind she runs], throughout the night, no need to fight, never a frown with golden brown'. With this, he suddenly relaxed back into his chair and started singing the song with his eyes half shut, swaying slightly from side to side. This provoked some laughter between us, and after confirming that I knew the song, he continued to sing, that is, before, much like with Lucy's account, another affect made itself known:

dud dud dud dud dud dud, dud dud dud dud dud dud (singing and swaying to the keyboard vamps in 3/4 bar). Right, or, I call her my brown (stops himself to explain), obviously it's a love/hate relationship with drug use... I call her a (pause) brown bitch, to be honest, because obviously she causes you so much pain but you still go running back to her, it's like a woman that makes you feel good when you're around her, she makes you feel good, but if you're 
without her, you're love sick, you're sick as a dog, you can't function without her, you're cold, you're sneezing, yeah, but when she's around you, you feel happy and when she's, like, when you're under the influence and you're wrapped around her, all you think about is her and you're happy to be in contact with her, but when she leaves you, you're love sick and you'll do anything, you'll do anything to get the feeling back, but yeah, heroin is a woman that treats me bad, but I still love her (emphasis put on this). Do you understand?

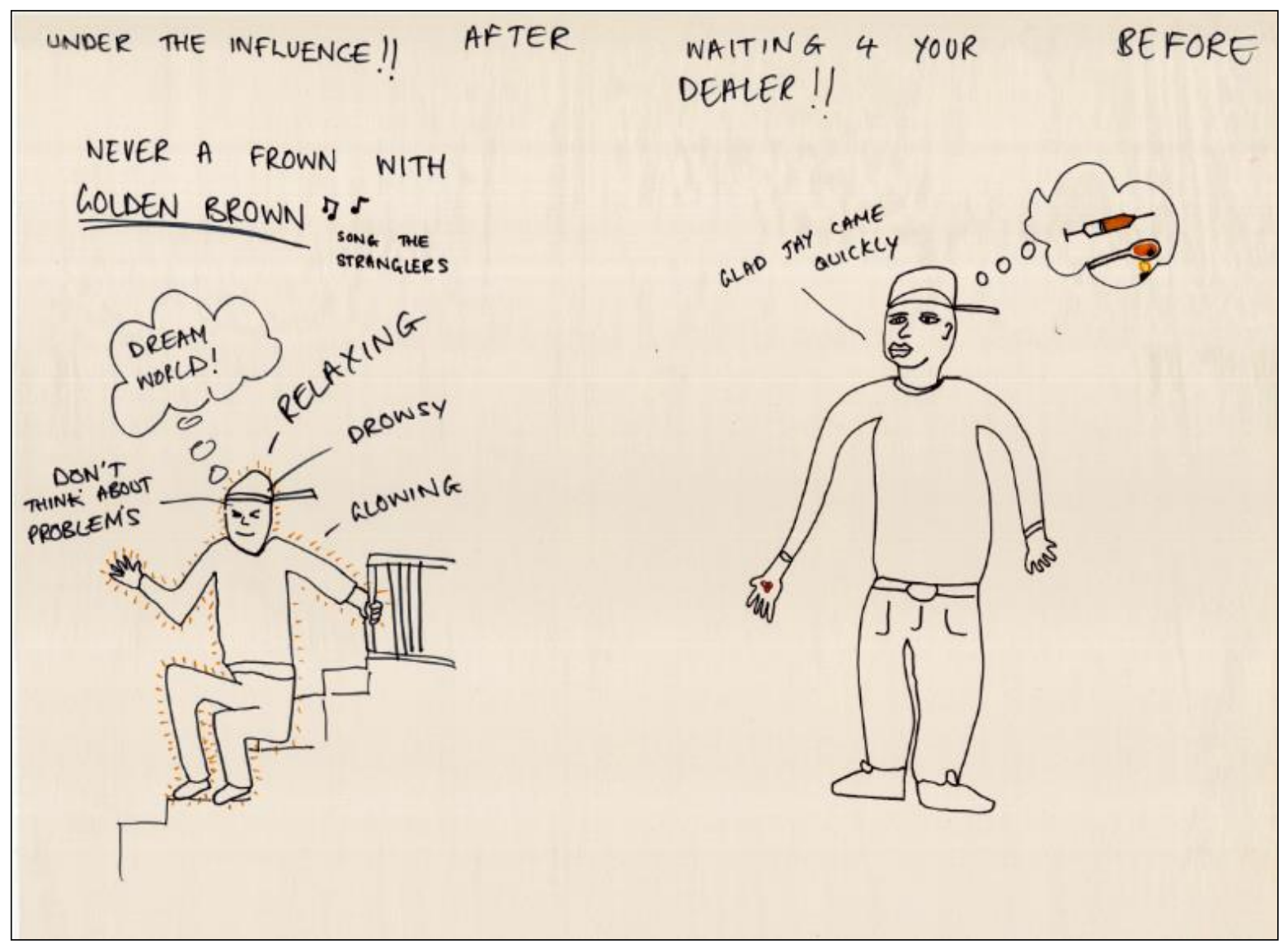

Figure III: Ajay's body map. (Jay is a psuedynym)

Ajay's account vividly highlights some of the complexities caught up in participants' feelings towards their drug use. He began by describing the feeling of heroin through the song lyrics and rhythms of 'golden brown' and affectively re-enacts the pleasures of being 'under the influence'. But then, like Lucy, he suddenly stops, as if again being cut off, and says, 'right'. This again gives us the sense that thoughts are not our own - the pleasurable memories escape him (perhaps, to use the worker's statement briefly mentioned above, he has 'forgotten how it was to enjoy [his] use'), and he starts to remember the bad side, or in Lucy's terms, 'the crap'. 
For Ajay, this is namely the role of dependency, which he personifies as 'girlfriend-like', perhaps to communicate an agency that is otherwise, in a 'modern' separation of objects and subjects, hard to explain (a device also used by others). Drawing on this agency, he poetically tells me about his conflict with the substance he loves but causes him so much pain.

The idea that pleasure can live outside the 'crap' makes little sense; instead it moves through networks, in 'passing' (Gomart \& Hennion, 1999). This 'passing' means it is always caught between affects. For example, some participants said there was not any pleasure in their drug use, it was purely 'addiction', and then they realised there was also pleasure. Others, like in Ajay's account, started off thinking about their drug use as simply pleasure-oriented - earlier in the interview Ajay said 'I use drugs because I enjoy using drugs that's the only reason I do use drugs'- but then realised there was also 'pain'. Conceiving of pleasure is hard because it is more often than not in passing, caught within networks and between affects as 'mixed feelings' (Lucy) and 'love/hate relationship' (Ajay), but also captured by other participants as 'sweet and sour' and 'good things and bad things'. By disrupting pleasure as free, we have been able to explore its more complicated and hidden forms. Next I turn to what this might mean for drug policy and intervention.

\section{DISCUSSION}

Where pleasure is becoming increasingly acceptable to talk about in relation to 'recreational' drug use, for example, the Global Drug Survey (the largest online drug survey) in 2013 introduced the first Net Pleasure Index, it is arguably becoming no more acceptable in relation to 'dependent use', for example, this Index notably excludes heroin and crack cocaine. In fact, a discourse of pleasure based on freedom could be making pleasure even less possible to discuss and exist among certain users, which could serve to inadvertently marginalise those involved in more complicated forms of drugged pleasures. Worryingly, these are likely to be those drug users that are already the most stigmatised. Therefore, I have argued, through participant accounts, for another way of understanding pleasure, as nearly always in tension, belonging neither to nature nor society, caught up in sociomaterial networks and between affects. By making pleasure more possible in these tightly managed contexts (e.g. the drug service), there is the potential to unleash many new ways of knowing, experiencing and also intervening with drugs. 
With a commitment to making better drug realities, a more complicated understanding of pleasure has uses in relation to recent phenomenon such as 'chemsex', where pleasure has been dealt with in constrained and constraining (stigmatising) ways (Race, 2015). A wider sense of 'pleasure-in-tension' can help acknowledge and engage with some of these most stigmatised forms of pleasure, enabling drug practitioners to talk more openly about these ways of experiencing drugs, which may help service users not only feel more understood, and thus willing to seek the support they need, but also enact more positive outcomes. A more complicated conception of pleasure allows for the ambivalence and ambiguity people often find in their using, both wanting to and not wanting to use. Rather than trying to purify these tensions, for example, in a cost/benefit analysis typical of the Cognitive Behavioural Therapyinformed techniques employed in UK drug services (DoH, 2007), workers can learn to hold onto them at the same time. That is, navigating harm reduction or treatment pathways in light of these tensions and conflicts, rather than trying to separate and privilege one (the 'costs') over the other ('benefits'). In a UK context, where treatment goals are increasingly defined by abstinence, such an understanding of pleasure will heighten an appreciation for the difficulties people have in holding only/mainly negative attitudes towards their drug use and making 'choices' to give them up (see also Mol, 2008 for a critique of choice-based care). This will make interventions such as heroin maintenance treatment seem less problematic as strategies that enact pleasure and addiction, drug and medicine, and drug user and patient.

Even in a harm reduction context, a recognition of pleasure highlights that technologies such as opiate substitution are not always enough in enabling safer practices. Where substances like methadone and buprenorphine deal with the physical symptoms of dependency and withdrawal, they cope less well with the other aspects of drug use, such as, the practices and pleasures. This recognition may even question the limits of harm reduction strategies such as supervised injecting clinics that carefully sanitise spaces. Rather than trying to manage such affects, harm reduction can tap into or 'harness' these aspects (Harris \& Rhodes, 2012). For instance, a sociomaterial take on pleasure gestures to the importance of the material environment, where certain experiences are afforded more or less than others. This may mean re-organising drug service spaces, and even harm reduction technologies, such as opiate substitution treatment (OST) regimes (e.g. Fraser \& valentine, 2008; Harris \& Rhodes, 2013) and substances (e.g. Dennis, 2017), and more recently injecting packs (Fraser et al, under review), with an awareness to what gets produced. This is a move marked by a shift away from freedom based on autonomy. As Emile Gomart famously argued in relation to methadone, 
'human agency is tentatively and temporarily re-defined as the capacity not to act alone, but [...] to act because one was generously constrained' (2002: 546). Following this, Harris and Rhodes argue for a more 'generous' OST strategy, which could enable people to 'manage their drug use, prevent withdrawal, cement social relationships, and inadvertently protect against hepatitis C transmission' (2013: 1). Fraser et al (under review) have also recently gone a step further in developing a new 'fitpack' prototype for couples, which they suggest can afford care and responsibility.

As researchers, practitioners and policy makers committed to the principles of harm reduction, we need to be thinking about ways to make pleasure and the other more hidden positive aspects of drug use more possible, that is, to produce more good affects in reducing bad affects, or more radically, to reduce bad affects in producing good affects. I have argued that one way to do this is in conceiving of pleasure in tension and so more complicated forms become knowable in research, practice and policy, which works to include rather than exclude people who inject drugs or use in ways commonly described as 'problematic', 'dependent' or 'chaotic' (often seen to be indicative of an addiction).

\section{CONCLUSION}

This article has shown how pleasure and addiction are produced as distinct. As a result, casting pleasure as freely chosen is highlighted as a modern project that relies on a separation of the social from the material, but, as predicted by Latour, despite these purification efforts, these divides started to elide. And as the antithetical dynamic of pleasure/addiction started to show itself up in this way (as a modern paradox), I was able to understand some of the complexities of what participants were telling me in a way that did not rely on such purifications. Pleasure was never conceived alone but rather always in tension with other affects. It is in these tensions that a wider recognition of pleasure in the drugs field is proposed. Importantly, this is one that allows for the pleasures experienced by people who are usually dismissed as addicted. Through a more inclusive, yet fraught conception, pleasure is not only more conceivable but also more possible (ontologically). Thus, not only are different kinds of policy and treatment conversations that look at the positive aspects of drug use as well as the harms made imaginable, but we can also be involved in bringing these aspects further into being through our interventions. 


\section{AKNOWLEDGLEMENTS}

I would like to wholeheartedly thank everybody who took the time to participate in this study. I would also like to thank my two PhD supervisors, Magdalena Harris and Tim Rhodes, for their dedicated support and guidance throughout the research process, and the generous and extremely constructive comments from all three reviewers on this manuscript. This work was supported by a PhD studentship from the Economic \& Social Research Council and a Mildred Blaxter Postdoctoral Fellowship from the Foundation for the Sociology of Health and Illness.

\section{REFERENCES}

American Psychiatric Association. (2013). Diagnostic and statistical manual of mental disorders (5th ed.). Washington, DC.

Askew, R. (2016). Functional fun: Legitimising adult recreational drug use. International Journal of Drug Policy. doi: http://dx.doi.org/10.1016/j.drugpo.2016.04.018

Berridge, K.C., Robinson, T.E. \& Aldridge, J.W. (2010). Dissecting components of reward: 'Liking', 'wanting', and learning. Current Opinion in Pharmacology 9(1), 65-73.

Brain, K. (2000). Youth, alcohol, and the emergence of the post-modern alcohol order. Institute of Alcohol Studies. Retrieved 10 Aug 2015 from www.isa.org.uk/iaspapers/branpaper.pdf

Bunton, R. \& Coveney, J. (2011). Drugs' pleasures. Critical Public Health 2(1), 19-23.

Carr, E.S. (2011). Scripting addiction: The politics of therapeutic talk and American society. Princeton; Oxford: Pinceton University Press.

Coleman, R. \& Ringrose, J. (2013). Deleuze and research methodologies. Edinburgh: Edinburgh University Press.

Deleuze, G. \& Guattari, F. (2004). A thousand plateaus: Capitalism and schizophrenia. London; New York: Continuum.

Demant, J. (2009) When alcohol acts: an actor-network approach to teenagers, alcohol and parties. Body \& Society 15(1), 25-46.

Dennis, F. (2016). Encountering 'triggers': Drug-body-world entanglements of injecting drug use. Contemporary Drug Problems 43(2), 126-141. 
Dennis, F. (2017). The injecting event: Harm reduction from a posthuman perspective. Critical Public Health 27(3), 337-349.

Department of Health (DoH) (2007). Drug Misuse and Dependence: UK Guidelines on Clinical Management. London: Department of Health (England), the Scottish Government, Welsh Assembly Government and Northern Ireland Executive

Duff, C. (2008). The pleasure in context. International Journal of Drug Policy 19(5), 384-392.

Duff, C. (2012). Accounting for context: Exploring the role of objects and spaces in the consumption of alcohol and other drugs. Social \& Cultural Geography 13(2), 145-159.

Duff, C. (2013). The social life of drugs. International Journal of Drug Policy 24(3), 167-172.

Duff, C. (2014). Assemblages of health: Deleuze's empiricism and the ethology of life. London; New York: Springer.

Dwyer, R. (2008). Privileging pleasure: Temazepam injection in a heroin market place. International Journal of Drug Policy 19(5), 367-374.

Featherstone, M. (1991). The body in consumer culture. In B. Turner (Ed) The body: social process and cultural theory (pp. 170-197). London: Sage Publications.

Foucault, M. (2007). Security, territory, population: Lectures at the Collège de France, 19771978. (Edited by M. Senellart \& A. I. Davidson). Basingstoke; New York: Palgrave Macmillan.

Fraser, S., Moore, D. \& Keane, H. (2014). Habits: Remaking addiction. Basingstoke: Palgrave Macmillan.

Global Drug Survey, (2013) Drug pleasure ratings. Retrieved on 6 April 2017 from https://www.globaldrugsurvey.com/past-findings/the-net-pleasure-index-results/

Gomart, E. \& Hennion, A. (1999). A sociology of attachment: Music amateurs, drug users. In J. Law \& J. Hassard (Eds) Actor Network Theory and After (pp. 220-248). Oxford: Blackwell/Sociological Review.

Gomart, E. (2002) Towards generous constraint: freedom and coercion in a French addiction treatment. Sociology of Health \& Illness 24(5), 5175-49.

Harris, M. \& Rhodes, T. (2012). Venous access and care: Harnessing pragmatics in harm reduction for people who inject drugs. Addiction 107(6), 1090-1096.

Harris, M. (2015). 'Three in the room': Embodiment, disclosure, and vulnerability in qualitative research. Qualitative Health Research 25(12), 1689-1699.

Holt, M. and Treloar, C. (2008) Pleasure and drugs. International Journal of Drug Policy 19(5), 349-352. 
Hunt, G. P. \& Evans, K. (2008). 'The great unmentionable': Exploring the pleasures and benefits of ecstasy from the perspectives of drug users. Drugs: Education, Prevention and Policy 15(4), 329-349.

Hutton, F. (2012). Harm reduction, students and pleasure: an examination of student responses to a binge drinking campaign. International Journal of Drug Policy 23(3), 229-235.

Latour, B. (1993). We have never been modern. Cambridge, Massachusetts: Harvard University Press.

Latour, B. (2004). How to talk about the body? The normative dimension of science studies. Body \& Society 10, 205-229.

Law, J. (2004). After method: Mess in social science research. London; New York: Routledge.

Lury, C. \& Wakeford, N. (Eds) (2012). Inventive methods: The happening of the social. Abington, Oxon; New York: Routledge.

MacLean, S. (2008) Volatile bodies: stories of corporeal pleasure and damage in marginalised young people's drug use. International Journal of Drug Policy 19(5), 3753-83.

Mason, J. (2010) Creative interviewing [Video file]. Retrieved from http://www.ncrm.ac.uk/resources/video/realities/creative.php

Measham, F. (2006). The new policy mix: Alcohol, harm minimisation, and determined drunkenness in contemporary society. International Journal of Drug Policy 17(4), 258268.

Mol, A. (2010). Actor-network theory: Sensitive terms and enduring tensions. Kölner Zeitschrift für Soziologie und Sozialpsychologie 50(1), 253-269.

Moore, D. \& Valverde, M. (2000). Maidens at risk: 'Date rape drugs' and the formation of hybrid risk knowledges. Economy \& Society 29(4, 514-531.

Nature (2014, February 6). Editorial: Animal farm. Nature 506: 5.

Nettleton, S., Neale, J. and Pickering, L. (2011) 'I don't think there's much of a rational mind in a drug addict when they are in the thick of it': towards an embodied analysis of recovering heroin users. Sociology of Health \& Illness 33(3), 3413-55.

O'Malley, P. \& Valverde, M. (2004). Pleasure, freedom and drugs: The uses of 'pleasure' in liberal governance of drug and alcohol consumption. Sociology 38(1), 25-42.

Pennay, A. (2012) Carnal pleasures and grotesque bodies: Regulating the body during a 'big night out' of alcohol and party drug use. Contemporary Drug Problems 39(3), 397428. 
Pennay, A. (2012). Carnal pleasures and grotesque bodies: Regulating the body during a 'big night out' of alcohol and party drug use. Contemporary Drug Problems 39(3), 397428.

Pienaar, K., Fraser, S., Kokanovic, R., Moore, D., Treloar, C., \& Dunlop, A. (2015). New narratives, new selves: Complicating addiction in online alcohol and other drug resources. Addiction Research \& Theory, 23(6), 499-509.

Race, K. (2015). Chemsex review: gay sex and drug use demand more careful forms of attention. The Conversation. Retrieved 7 November 2015 from http://theconversation.com/chemsex-review-gay-sex-and-drug-use-demand-morecareful-forms-of-attention-51586

Reith, G. (2004). Consumption and its discontents: addiction, identity and the problems of freedom. The British Journal of Sociology 55(2), 283-300.

Ritter, A. (2014) Where is the pleasure? Addiction 109(10), 15871-588.

Rose, N. (1999). Powers of freedom. Cambridge: Cambridge University Press.

Rose, N., O’Malley, P. \& Valverde, M. (2006). Governmentality. Annual Review of Law \& Social Science 2, 83-104.

Rose, N., O’Malley, P. \& Valverde, M. (2006). Governmentality. Annual Review of Law and Social Science 2, 831-04.

Schnuer, G. (2013). Pleasure and excess: Using Georges Bataille to locate an absent pleasure of consumption. Addiction Research \& Theory 21(3), 2582-68.

Sedgwick, E. K. (1993). Epidemics of the will. In E.K. Sedgwick. Tendencies (pp. 130-143). Durham: Duke University Press.

Shapin, S. \& Schaffer, S. (1985). Leviathan and the air-pump: Hobbes, Boyle, and the experimental life. Princeton: Princeton University Press.

Stewart, K. (2007). Ordinary affects. Durham; London: Duke University Press.

Szmigin, I. T., Griffin, C., Hackley, C., Bengry-Howell, A. \& Mistral, W. (2008). Re-framing 'binge drinking' as calculated hedonism: Empirical evidence from the UK. International Journal of Drug Policy 19(5), 3593-66.

valentine, k. \& Fraser, S. (2008). Trauma, damage and pleasure: Rethinking problematic drug use. International Journal of Drug Policy 19(5), 410-416.

Vargas, E. V. (2010). Tarde on drugs, or measure against suicide. In M. Candea (Ed) The social after Gabriel Tarde: Debates and assessments (pp. 208-30). London: Routledge.

Weinberg, D. (2002) On the embodiment of addiction. Body \& Society 8(4), 1-19. 
Weinberg, D. (2013) Post-humanism, addiction and the loss of self-control: Reflections on the missing core in addiction science. International Journal of Drug Policy 24(3), 173181. 